\title{
Childhood vs adulthood health and cleanliness on educational outcome in Indonesia: moving towards Sustainable Development Goals
}

\author{
Restananda Nabilla Yusacc ${ }^{1 *}$ and Irfani Fithria Ummul Muzayanah ${ }^{2}$ \\ ${ }^{1}$ Department of Economics, Faculty of Economics and Business, University of Indonesia
}

\begin{abstract}
As a key indicator in Sustainable Development Goals, good health and well-being, also clean water and sanitation is studied in this research. In Indonesia where infrastructure development is still advancing, the difference of those infrastructure when people are in childhood and adulthood could be very different. It is also interrelated to their health status. Early health is considered as important, if not more, to current health as in early years there are primary development happened to an individual, whether it is internal or external. Health is also linked to productivity such as educational outcomes. This study aims to explain the relationship of health and cleanliness between childhood and adulthood on educational outcomes. Using IFLS 5 data and multinomial logistic, the result is while cleanliness and infrastructure in childhood is found to be more important for higher education, current health and early health is just as strong.
\end{abstract}

\section{Background}

Good health and well-being is a key indicator in Sustainable Development Goals. It is the $3^{\text {rd }}$ goal in Sustainable Development Goals. Well-being with objective approach can be measured from education, environment, economic, and health. One of the approach, health is unique since it can be measured not only from an individual's general health, but also from their environment that generates direct and indirect impact such as clean water and sanitation. Clean water and sanitation is also a key indicator in Sustainable Development Goals. The availability to clean water and sanitation might be overlooked by those who never lack of them, but they are basic needs that shaped cleanliness and health of an individual or community. Health has a relationship with education that is linked to productivity. Those who are healthy and reside in healthy environment is more likely to benefit from this by having lower risk of prone to sickness, and vice versa. Not only the current status, early well-being is also important since it occurs in crucial stage of life, which is in primary education. A majority of an individual development occurred at earlier age, such as the ability to walk, talk, read and others. Health condition on this stage is

\footnotetext{
* Corresponding author: rnyusacc@gmail.com
} 
important since it determines successful development. Also, children who are healthy is more likely to have higher school days attended and higher probability of successful educational attainment. Parents also played a key role in children's health as primary caregiver. Parents with higher understanding for healthy behavior, in other words parents with higher educational attainment, determines children's health status. In adulthood, it still determines our ability to be productive. Early well-being is important due to it being on the primary development stage but current well-being is what determines current outcome. Both of them are important but one may be weighing heavier than other. Especially for those with medical condition, the likelihood it occur in childhood and disappear in adulthood and vice versa is a possibility and whether the health and cleanliness condition in childhood or adulthood that could determine educational outcomes. The understanding of life-cycle such as adding into account both childhood and adulthood is important due to the experiences could affect the former or latter in many ways. Therefore, this study aims to explain the relationship of health and cleanliness between childhood and adulthood on educational outcomes.

\section{Review \& methodology}

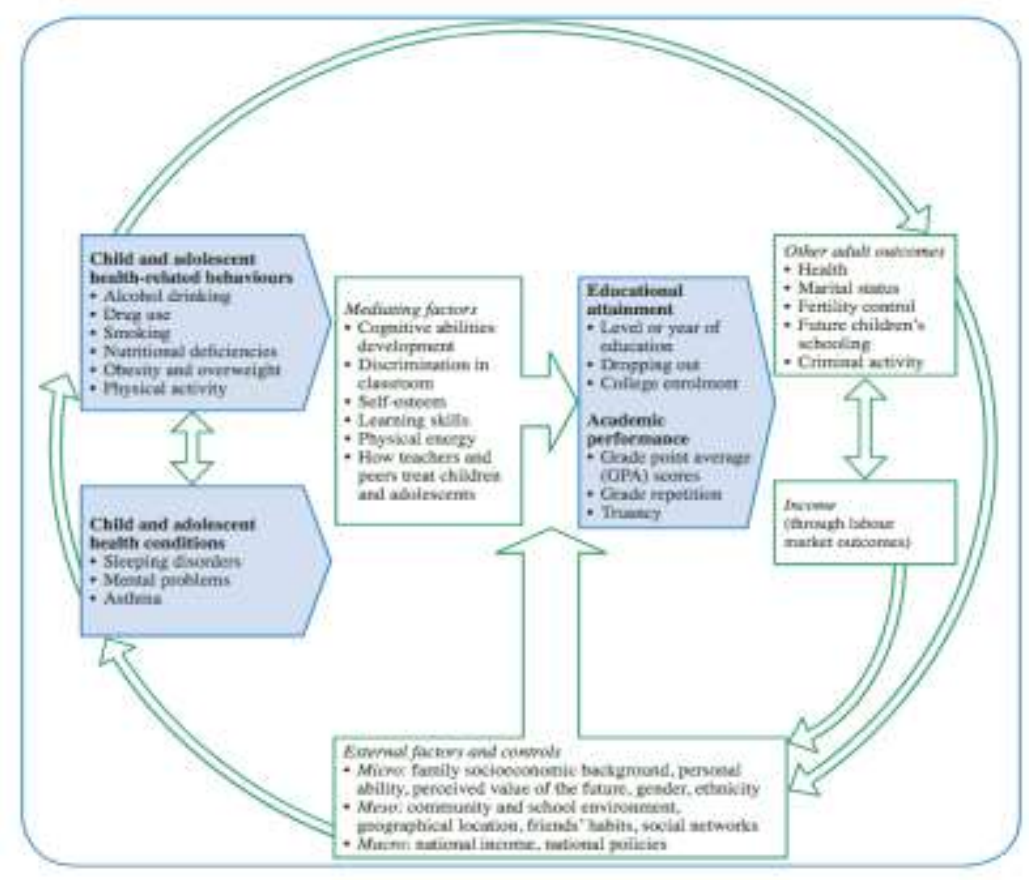

Fig. 1. Circular Flow of Health and Education Relationship [1].

There are numerous body of literature on the relationship between health and education, such as Grossman [2] and more recently by other authors including Cutler and LlerasMuney [3]; Ding et al. [4]; Gan and Gong [5], health and education relationship can be explained in three ways: 
1. education might determine health $\bigotimes$

2. one or more other factors might determine both health and education simultaneously

3. health might determine education

It can be seen that an individual's perception on education is an investment, it generates incentive to be healthy and get the benefits from it. Education can also make an individual maintain and improve their health due to enhanced insights on health problems. Since better educational attainment is linked with higher earnings, it could translate to higher spending on health and better health in general. Health can also be explained by family socioeconomic characteristics, since it determines the behavior and knowledge on health.

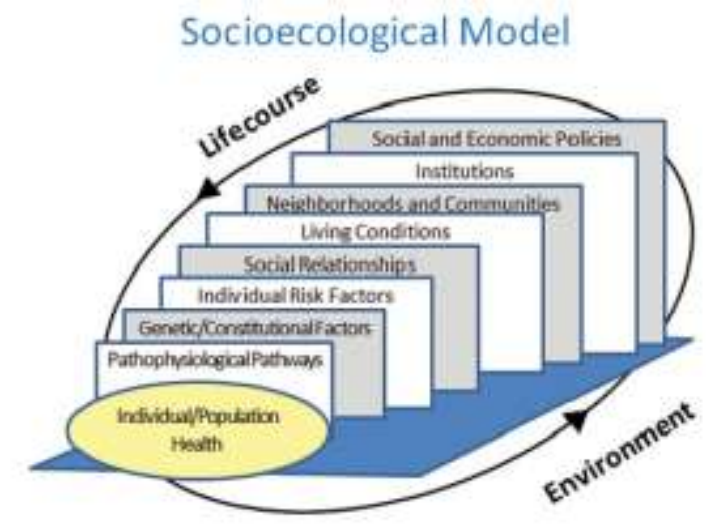

Fig. 2. Socioecological Model [6].

Education is particularly linked to several mechanisms that could situate an individual's outcomes in many contexts such as ecological contexts. It served as a foundation to choices taken by individuals, such as relationships and career path. Therefore, this model can explain many ways that education is linked to life experiences, such as health and cleanliness behavior. It is also the key to understand how educational outcomes are the force behind social and environmental contexts in our life and how it affected individual experiences.

One of the key indicator in social research is educational outcomes such as years of schooling. The factor being it is constantly measured and there are many dimensions in education that is important to understand more such as quality of education, cognitive and character development, and more. Educational attainment with health and cleanliness behavior or infrastructure's relationship can be explained in many ways. A literature by Montez et al. showed that years of schooling and risk of mortality is negatively related. Thus, it is important to understand the factors behind.

This study is using the data available from Indonesia Family Life Survey (IFLS) 5 that was published in 2014, which provides a comprehensive data on both household and individual level in economic well-being (consumption, income, and assets); education, migration, and labor market outcomes; marriage, fertility, and contraceptive use; health status, use of health care, and health insurance; relationships among co-resident and nonco-resident family members; processes underlying household decision-making; transfers among family members and inter-generational mobility; and participation in community activities. It adds cognitive, personality, and subjective well-being in its most recent version. IFLS is a survey conducted by RAND Corp and SurveyMETER in 13 provinces of 
Indonesia. It had been conducted for 5 (five) waves, in 1993, 1997, 2000, 2007, and 2014. IFLS follows households through generation of families interviewed in IFLS 1 which represented $83 \%$ of the Indonesian population.

This study will employ econometrics model using Multinomial Logistic. Multinomial logistic (mlogit) regression is a method that generalized logistic regression to multiclass problems to predict a nominal dependent variable with more than two groups. In this case our dependent variable contains six groups of educational level, zero represent no education, one represent primary education, two represent secondary education, three represent high school education, four represent diploma education, and five represent university education. Unit of analysis consisted of all adult over 21 years old. The number of sample is 51.447 , with $49 \%$ men and $51 \%$ women. The sample's average age is 40 years old. $59 \%$ of the sample reside in urban area while $41 \%$ live in rural area.

$$
\begin{aligned}
& \ln \left(\frac{P(1)}{P(0)}\right)=\beta 0+\beta 1 \text { sex }+\beta 2 \text { age }+\beta 3 \text { residence }+\beta \text { 4electricity } \text { adult }+\beta 5 \text { water }_{\text {adult }}+\beta 6 \text { toilet }_{\text {adutt }} \\
& +\beta 7 \text { electricity } \text { child }+\beta 8 \text { water }_{\text {child }}+\beta 9 \text { toilet }_{\text {child }}+\beta 10 \text { health }_{\text {child }} \\
& +\beta 11 \text { school } l_{\text {chld }}+\beta 12 \text { health }_{\text {afult }}+e \\
& \ln \left(\frac{P(5)}{P(0)}\right)=\beta 0+\beta 1 \text { sex }+\beta 2 \text { age }+\beta 3 \text { residence }+\beta 4 \text { electricity } \text { adult }+\beta 5 \text { water }_{\text {adult }}+\beta 6 \text { toilet } \text { advit }_{\text {alt }} \\
& +\beta \text { electricity }_{\text {child }}+\beta 8 \text { water }_{\text {child }}+\beta 9 \text { tollet }_{\text {shild }}+\beta 10 \text { heulth }_{\text {child }} \\
& +\beta 11 \text { school } \mathrm{l}_{\text {chlld }}+\beta 12 \text { health }_{\text {adult }}+e
\end{aligned}
$$

In this model, we want to see the likelihood of the sample's health and cleanliness behavior in childhood and adulthood to their educational level. It is suggested that the result might be linear, when health and cleanliness is higher than the educational level is also higher. Sex, age, and place of residence (urban-rural) is used as controlling variables. Variables that is questioned on their childhood experience which is when they were 12 years old are electricity utilization, water source, toilet source, and perceptive on general health whether they are healthy or not on a scale one to five, five being the healthiest.

\section{Estimation \& discussion}

The result suggested that some of the variables has stronger relation when educational level is higher. Utilization of electricity is one of them. Electricity could boost productivity as it helps to stay productive under the unavailability of sun light. As education level goes up, the relation with electricity is also stronger but the highest is with high school graduates. However, the result is stronger when questioned in childhood. This is an interesting result which indicates those with higher education utilize electricity more in their early years, or staying productive after the sun has set more than their counterparts. Cleanliness as in where the individual goes to the toilet is also important since it is stronger as the education level goes up, and like electricity it is stronger in childhood. As the education level goes higher, individuals tend to have cleaner toilet facility and inside or closer to home. For water source, the same result occurred which is when water source for drinking is more sanitary and shared for household only, level of education is also higher in the future. But 
for perception on health in childhood and adulthood, where the higher is the healthier, the relation with educational outcomes is found as strong as each other and the difference is minor. This indicates that both early health and current health is important.

Based from the result, cleanliness and infrastructure in childhood is an important indicator of educational outcomes. This also indicates that since childhood in this study is 12 years old which is in primary education, those with better facilities especially in cleanliness when childhood tend to have better opportunity for educational outcomes since they could be comfortable to focus on learning. Since current health and early health is both as strong, it could indicate that there is not much discrepancy between early health and current health. Those who are in certain level in their childhood tend to stay in the same level in their adulthood. For those who bear medical conditions since childhood it is a possibility it stays until their adulthood and their condition is the same.

\section{Conclusion}

Health and cleanliness is an important indicator for an individual's welfare. It is linked to their productivity such as educational outcomes. This study has found that educational outcomes is determined by health and cleanliness both in childhood and adulthood. However, cleanliness in childhood is found to has stronger linkage to better educational outcome. Better facilities in childhood means that an individual could live comfortably and focus on learning while their counterparts might not have the same luxury and there is a trade-off between learning among other things. Early health and current health did not show much difference since both of them is interrelated and indicate little change between early and current health. But still it is important as healthy individual could have higher school attendance, therefore better educational outcomes.

Since Indonesian government is currently advancing infrastructure, it is worth noted that aside from public infrastructure such as utilization of electricity, household facilites like water source and toilet usage should not be overlooked since it is directly involved with individual's daily life and could shape their lives and productivity. Better facilities for now means better facilities for someone's childhood in the future and it is hoped that with this, Indonesia could attain higher educational outcome.

\section{References}

1. M. Suhrcke, C. de Paz Nieves, The impact of health and health behaviours on educational outcomes in high-income countries: a review of the evidence (WHO Regional Office for Europe, Copenhagen, 2011)

2. M. Grossman, The correlation between health and schooling (Cambridge, MA, 1973)

3. D.M. Cutler, A. Lleras-Muney, Education and health:evaluating theories and evidence (Cambridge, MA, 2006) 
4. W. Ding et al., The impact of poor health on education: new evidence using genetic markers (Cambridge, M, 2006)

5. L. Gan, G. Gong, Estimating interdependence between health and education in a dynamic model (Cambridge, MA, 2007)

6. G.A. Kaplan, S.A. Everson, J.W. Lynch, The contribution of social and behavioral research to an understanding of the distribution of disease: a multilevel approach (National Academies Press, Washington, DC, 2000). 